Arq. Bras. Med. Vet. Zootec., v.61, n.5, p.1139-1147, 2009

\title{
Teores de proteína para vacas lactantes em pastejo de capim-elefante
}

\author{
[Protein contents for lactating dairy cows grazing elephant grass]
}

\author{
F.R. Pereira ${ }^{1}$, H.M. Saturnino ${ }^{2}$, E.O.S. Saliba ${ }^{2}$, L.C. Gonçalves ${ }^{2}$, R.B. Reis ${ }^{2}$, P.A.B. Miranda ${ }^{3}$, R.C. \\ Mourão $^{3}$, D.T. Silvetre ${ }^{3}$, P.N.S. Caldeira ${ }^{4}$ \\ ${ }^{1}$ Instituto Estadual de Florestas - Belo Horizonte, MG \\ ${ }^{2}$ Escola de Veterinária - UFMG - Belo Horizonte, MG \\ ${ }^{3}$ Médico veterinário autônomo \\ ${ }^{4}$ Zootecnista autônomo
}

\begin{abstract}
RESUMO
Avaliou-se o efeito da utilização de concentrados com diferentes teores de proteína bruta (PB) para vacas em lactação sob pastejo rotacionado de capim-elefante, distribuídas em três quadrados latinos (3x3). Os tratamentos foram concentrados suplementares contendo 15,$2 ; 18,2$ ou $21,1 \%$ de PB. Foram oferecidos $3 \mathrm{~kg}$ de concentrado por vaca, duas vezes ao dia. A disponibilidade de matéria seca (MS)/ha de capimelefante foi de $1.873 \mathrm{~kg}$ ou de $17,4 \mathrm{~kg}$ de MS/vaca dia ${ }^{-1}$. A MS do capim-elefante foi de $19,6 \%$, contendo $13,9 \%$ de $\mathrm{PB}$ e $66,1 \%$ de fibra detergente neutro (FDN) e $67,4 \%$ de digestibilidade in vitro da MS (DIVMS). Não houve diferença ( $\mathrm{P}>0,05)$ entre os tratamentos quanto ao consumo diário de MS da dieta total $(21,5 ; 21,6$ e $20,8 \mathrm{~kg} / \mathrm{d})$, MS do capim-elefante $(16,1 ; 16,3$ e $15,5 \mathrm{~kg} / \mathrm{d})$ e FDN do capim-elefante $(10,7 ; 10,7$ e $10,3 \mathrm{~kg} / \mathrm{d})$. As produções de leite $(17,5 ; 17,2$ e $17,6 \mathrm{~kg} / \mathrm{d})$ e os teores de gordura $(3,4 ; 3,5 \mathrm{e}$ $3,5 \%)$, proteína $(2,9 ; 2,9$ e $2,9 \%)$, lactose $(4,4 ; 4,4$ e $4,4 \%)$ e $\mathrm{N}$-ureia no leite $(14,1 ; 14,6$ e $15,8 \mathrm{mg} / \mathrm{dL})$ não diferiram $(\mathrm{P}>0,05)$ entre os tratamentos (respectivamente, para 15,$2 ; 18,2$ ou $21,1 \%$ de $\mathrm{PB})$. $\mathrm{O}$ teor de $\mathrm{N}$-ureia no plasma foi maior $(\mathrm{P}<0,05)$ em vacas alimentadas com concentrado com $21,1 \%$ de $\mathrm{PB}$ (na ordem citada: 11,$5 ; 12,2$ e $14,4 \mathrm{mg} / \mathrm{dL}$ ). Nas condições experimentais, o concentrado suplementar com $15,2 \%$ de PB pode ser utilizado na alimentação de vacas em lactação em pastagem de capim-elefante.
\end{abstract}

Palavras-chave: vaca, lactação, capim-elefante, proteína, suplementação

\begin{abstract}
To evaluate the effect of feeding concentrate with different crude protein $(C P)$ contents, lactating dairy cows grazing elephant grass were distributed in a $3 \times 3$ latin square. Three $\mathrm{kg} /$ cow of concentrates (15.2, 18.2 , or $21.1 \%$ CP) were offered twice a day. Elephant grass dry matter (DM) availability was $1,873 \mathrm{~kg} / \mathrm{ha}$; with a daily offer of $17.4 \mathrm{~kg} / \mathrm{cow}$. The elephant grass DM content was $19.6 \%$ with $13.9 \% \mathrm{CP}$, $66.1 \%$ neutral detergent fiber $(N D F)$, and $67.4 \%$ in vitro DM digestibility. There was no difference among treatments regarding total diet DM daily intake $(21.5,21.6$, and $20.8 \mathrm{~kg} / \mathrm{cow})$, elephant grass DM $(16.1,16.3$, and $15.5 \mathrm{~kg} / \mathrm{cow})$, and elephant grass $\operatorname{NDF}(10.7,10.7$, and $10.3 \mathrm{~kg} / \mathrm{cow})$. Milk yield $(17.5$, 17.2 , and $17.6 \mathrm{~kg} / \mathrm{d})$ fat $(3.4,3.5$, and $3.5 \%$ ), protein $(2.9,2.9$, and $2.9 \%)$, lactose (4.4, 4.4, and $4.4 \%)$, and $N$-urea $(14.1,14.6$, and $15.8 \mathrm{mg} / \mathrm{dL})$ did not differ among concentrates $(P>0.05)$. Plasma $N$-urea was higher in cows fed concentrate with $21.1 \% C P(11.5=12.2<14.4 \mathrm{mg} / \mathrm{dL}, P<0.05)$. According to these results, concentrate with $15.2 \% \mathrm{CP}$ can be used to lactating dairy cows grazing elephant grass, without affecting milk production as compared to concentrate with 18.2 or $21.1 \%$ of CP.
\end{abstract}

Keywords: cow, lactation, elephant grass, protein, supplementation

Recebido em 15 de maio de 2008

Aceito em 25 de setembro de 2009

E-mail: fredericorache@hotmail.com 


\section{INTRODUÇÃO}

Pelas condições ambientais, sociais e econômicas, as pastagens constituem a base da alimentação da pecuária de leite, principalmente na primavera e no verão, caracterizadas por temperaturas elevadas e alta precipitação. Nessa época, o capim-elefante apresenta-se com potencial para ser ofertado em grande quantidade, com alto valor nutritivo e baixo custo. Em sistemas de alimentação exclusiva com capim-elefante sob pastejo, devido às características intrínsecas dessa forrageira, a produção de leite limita-se a valores médios de 11,5kg/d (Lucci et al., 1972; Deresz, 2001). Produções mais altas só foram possíveis quando vacas receberam concentrado suplementar.

A estratégia de suplementação deve considerar os aspectos nutritivos do suplemento (Paulino et al., 2002) como ingestão, composição e digestão (Bargo et al., 2003), os quais associados às deficiências impostas pelo capim, atendam às exigências dos animais (Paulino et al., 2002; Bargo et al., 2003).

Normalmente, para vacas com produções de leite acima de $15,0 \mathrm{~kg} / \mathrm{d}$, são disponibilizados no mercado varejista concentrados com teores de proteína bruta (PB) acima de 20\%, para suplementação de qualquer tipo de volumoso. Para Santos et al. (2003), a utilização de concentrados com 16 a $18 \%$ de PB, ao invés de formulações com 20 a $24 \%$ de PB normalmente observadas em sistemas que utilizam pastagens de qualidade como base da alimentação de vacas em lactação, pode diminuir o custo de suplementação, sem comprometer a produção. Estudos neste sentido são escassos na literatura.

Os objetivos desta pesquisa foram avaliar o desempenho de vacas em lactação alimentadas com capim-elefante sob pastejo rotacionado e concentrados suplementares com 15; 18 ou $21 \%$ de $\mathrm{PB}$ e caracterizar quanti-qualitativamente o capim-elefante.

\section{MATERIAIS E MÉTODOS}

O experimento foi realizado entre 26 de dezembro de 2003 e 26 de fevereiro de 2004 . O manejo do capim-elefante, sob rotação animal, foi baseado na exploração de perfilhos aéreos
(Corsi et al., 1998), com período de ocupação de um a dois dias e período de descanso de 28 a 45 dias, em função da disponibilidade de capim e do resíduo pós-pastejo (avaliado visualmente, evitando o super ou o subpastejo). A taxa de lotação foi de 3,8 vacas/ha. Foram feitas adubações de $100 \mathrm{~kg} \mathrm{~N}, 50 \mathrm{~kg}$ de $\mathrm{K}_{2} \mathrm{O}$ e $50 \mathrm{~kg}$ de $\mathrm{P}_{2} \mathrm{O}_{5} /$ ha/ano distribuídas em quatro ciclos de pastejo, na estação das chuvas.

Estimou-se a disponibilidade do capim-elefante, antes da ocupação dos piquetes, pelos procedimentos de rotina para experimentos dessa natureza (Penati, 2002), sendo a altura de corte semelhante à altura do resíduo pós-pastejo (Deresz, 2001). Do material cortado, foram colhidas amostras e analisaram-se os teores de $\mathrm{PB}$, matéria seca (MS) e digestibilidade in vitro da matéria seca (DIVMS) pela técnica de espectofotometria de refletância no infravermelho proximal $^{1}$ e fibra em detergente neutro (FDN), seguindo procedimentos descritos por Silva (1990).

Os ingredientes utilizados e a composição dos concentrados (Tab. 1) foram baseados nas análises dos teores de MS, PB, FDN e DIVMS, seguindo procedimentos descritos por Silva (1990) e nos valores de $\mathrm{Ca}$ e $\mathrm{P}$, segundo Valadares Filho et al. (2002). Os concentrados foram fornecidos, para cada vaca individualmente, $3 \mathrm{~kg}$ após a ordenha da manhã e $3 \mathrm{~kg}$ antes da ordenha da tarde.

Foram utilizadas nove vacas mestiças Holandês/Zebu 15/16 e 31/32, sendo três primíparas, com média de 117 dias em lactação e produção de 17,4kg/d de leite, e seis multíparas, com média de 97 dias em lactação e produção de $22,2 \mathrm{~kg} / \mathrm{d}$ de leite.

As vacas foram distribuídas em três quadrados latinos $(3 \times 3)$, sendo dois quadrados compostos pelas multíparas e o terceiro pelas primíparas. Os quadrados latinos eram contemporâneos e divididos em três períodos com durações de 21 dias cada, sendo 14 dias de adaptação e sete dias de coleta de dados.

\footnotetext{
${ }^{1}$ NIRS - modelo NIRVIS - Buhler Ltda - Uzwil, Suiça.
} 
Tabela 1. Ingredientes utilizados, teores de matéria seca (MS), proteína bruta (PB), fibra em detergente neutro (FDN), digestibilidade in vitro da MS (DIVMS), cálcio (Ca) e fósforo (P) dos concentrados

\begin{tabular}{cccc}
\hline & \multicolumn{3}{c}{ PB no concentrado (\%) } \\
\cline { 2 - 4 } & 15,2 & 18,2 & 21,1 \\
\hline Ingrediente (\%) & & 30,15 & 37,9 \\
Farelo de soja & 22,4 & 66,5 & 58,5 \\
Polpa cítrica & 74,5 & 0,35 & 0,7 \\
Calcário calcítico & - & 1,4 & 1,3 \\
MAP & 1,5 & 1,6 & 1,6 \\
Outros minerais & 1,6 & & 89,9 \\
Composição química (\%) & & 89,9 & 19,6 \\
MS & 89,4 & 20,1 & 85,8 \\
FDN & 20,6 & 86,5 & 1,44 \\
DIVMS & 87,3 & 1,43 & 0,57 \\
Ca & 1,42 & 0,56 & \\
P & 0,56 & &
\end{tabular}

MAP: fosfato monoamônico

O consumo de capim-elefante foi estimado indiretamente em função da digestibilidade dos alimentos e da produção fecal, e a produção fecal foi estimada com o uso de LIPE $\AA^{2}$ como indicador externo, conforme Saliba et al. (2003).

As vacas foram ordenhadas duas vezes ao dia às $7 \mathrm{~h}$ e $14 \mathrm{~h}$, e a produção de leite medida diariamente, do $15^{\circ}$ ao $21^{\circ}$ dia de cada período experimental. No $20^{\circ}$ e no $21^{\circ}$ dia, foram coletadas amostras distintas (manhã e tarde) para análise dos teores de proteína, gordura e lactose, pela técnica de absorção do comprimento de onda na região infravermelho ${ }^{3} \mathrm{e}$ N-ureia no leite (NUL), pelo teste enzimático colorimétrico ${ }^{4}$. Foram feitas correções da produção de leite para $4 \%$ de gordura (CPG), segundo o NRC (Nutrient..., 2001).

Para análise de N-ureia no plasma (NUP), foram coletadas amostras de sangue das vacas, por punção da veia jugular (primeiro período) e mamária (segundo e terceiro períodos), aproximadamente cinco horas após a alimentação da manhã, no $20^{\circ} \mathrm{e}$ no $21^{\circ}$ dia de cada período experimental. A mudança da veia coletada foi para facilitar o manejo na coleta. O NUP foi analisado pelo teste enzimático colorimétrico ${ }^{5}$.

Os animais foram pesados por dois dias consecutivos, no início do experimento e no final

${ }^{2}$ Lignina Purificada e Enriquecida - Belo Horizonte, Brasil. ${ }^{3}$ Bentley 2000 - Bentley Instruments Inc - Chascka - Minn, EUA.

${ }^{4}$ Bentley Chemspec 150 - Bentley Instruments Inc - Chascka - Minn, EUA.

${ }^{5}$ Kit Bioquímico Bioclin - Química Básica Ltda - Belo Horizonte, Brasil. de cada período experimental, após a ordenha da manhã.

Os quadrados latinos para análises estatísticas do consumo, da produção e dos componentes (gordura, proteína e lactose) do leite e da concentração de NUP foram analisados em conjunto, sendo consideradas as fontes de variação: vaca, tratamento (concentrado), período, ordem de lactação (primíparas ou multíparas) e interação tratamento $\mathrm{x}$ ordem de lactação. Além da comparação de média entre todos os animais, também foi feita comparação entre primíparas e multíparas, sempre utilizando o teste $\mathrm{t}$, a $5 \%$ de probabilidade.

Para produção de leite sem e com CPG, foi computada uma parcela perdida (perda de um grau de liberdade) sofrida por uma das vacas, que apresentou produção de leite discrepante e inferior às demais, durante os dias de coleta no segundo período, por ter tido mastite. Os resultados das análises de NUL, devido à ocorrência de perda de todos os dados coletados no último período experimental, foram analisados utilizando-se delineamento estatístico em blocos ao acaso, sendo cada período experimental (primeiro e segundo) equivalente a um bloco. As médias foram comparadas pelo teste $\mathrm{t}$ com $5 \%$ de probabilidade (Sampaio, 2002).

\section{RESULTADOS E DISCUSSÃO}

$\mathrm{Na}$ Tab. 2, estão os dados climáticos antes e durante o período experimental. 
Tabela 2. Dados climáticos nos períodos pré-experimental e experimental

\begin{tabular}{|c|c|c|c|c|c|c|c|c|}
\hline & \multirow{2}{*}{$\begin{array}{c}\text { Chuvas }^{1} \\
\text { (mm) } \\
\text { Acumulado } \\
\end{array}$} & \multicolumn{3}{|c|}{$\begin{array}{l}\text { Temperatura }^{2} \\
\left(\mathrm{C}^{\circ}\right) \text { média }\end{array}$} & \multirow{2}{*}{$\begin{array}{l}\text { Umidade } \\
\text { relativa do } a^{2} \\
(\%) \text { Média }\end{array}$} & \multirow{2}{*}{ 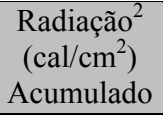 } & \multicolumn{2}{|c|}{$\begin{array}{c}\text { Nebulosidade }^{2}(0 / 10) \\
\text { média }\end{array}$} \\
\hline & & Média & Máx. & Mín. & & & Manhã & Tarde \\
\hline Setembro & 18,3 & 21,9 & 27,7 & 17,7 & 57 & - & 6 & 5 \\
\hline Outubro & 20,6 & 22,8 & 28,9 & 18,3 & 54 & - & 6 & 6 \\
\hline Novembro & 163,2 & 23,0 & 28,6 & 18,8 & 66 & - & 7 & 8 \\
\hline Dezembro & 220,0 & 23,9 & 29,1 & 19,9 & 69 & - & 6 & 7 \\
\hline Janeiro & 335,1 & 22,5 & 27,0 & 19,5 & 82 & 5.185 & 8 & 8 \\
\hline Fevereiro & 311,5 & 22,5 & 26,9 & 18,5 & 84 & 4.512 & 8 & 8 \\
\hline
\end{tabular}

${ }^{\mathrm{D}}$ Dados coletados no local; ${ }^{2}$ Fonte: INMET $-5^{\circ}$ distrito, aproximadamente $50 \mathrm{~km}$ do local.

A disponibilidade média estimada de capimelefante foi de $1.873 \mathrm{~kg}$ de $\mathrm{MS} / \mathrm{ha}$, considerada baixa diante das variações de 1.555 a $2.950 \mathrm{~kg}$ de $\mathrm{MS} /$ ha, obtidas no verão (Aroeira et al., 1999; Deresz, 2001). Isso pode estar associado ao clima, caracterizado por longos períodos de dias nublados e temperaturas amenas, e também à fertilidade do solo e à moderada adubação adotada, que podem ter limitado o crescimento do capim. Porém, pelas variações no período de ocupação, a oferta de capim não fícou prejudicada $(17,4 \mathrm{~kg}$ de $\mathrm{MS} / \mathrm{vaca} / \mathrm{dia})$ e foi considerada boa diante das variações de 9,2 a 17,0kg de MS/vaca/dia (Aroeira et al., 1999; Deresz, 2001).

O teor médio de $19,6 \%$ de MS ficou dentro do previsto para capim-elefante sob pastejo, com descanso entre 28 e 45 dias (Lucci et al., 1972; Vilela et al., 1972). O teor médio de $13,9 \%$ de PB na MS foi considerado alto diante da variação de 9,4 a 14,5\% de PB na MS, observada no capim-elefante sob pastejo, na época das chuvas (Vilela et al., 1972; Silva et al., 2002). O teor médio de $66,1 \%$ de FDN na MS foi considerado baixo, tendo em vista a variação de 66,5 a $72,2 \%$ de FDN na MS, observada em capim-elefante sob pastejo (Benedetti, 1994; Silva et al., 2002). O valor médio de $67,4 \%$ de DIVMS foi considerado alto, diante dos valores de 57,2 a 66,0\% de DIVMS observados em capim-elefante sob pastejo, no verão (Benedetti, 1994; Aroeira et al., 1999). Desse modo, o capim-elefante apresentou-se com bom valor nutritivo, devido ao elevado teor de PB e DIVMS e ao baixo teor de FDN.

Os consumos de MS total e de MS e FDN do capim-elefante não variaram $(\mathrm{P}>0,05)$ em função dos teores de PB do concentrado suplementar (Tab. 3).

Tabela 3. Consumos de matéria seca (MS) da dieta total, do capim-elefante e da fibra em detergente neutro $(\mathrm{FDN})$ do capim-elefante por todas as vacas (T), pelas primíparas (P) e pelas multíparas (M), alimentadas com capim-elefante sob pastejo e concentrado suplementar com diferentes teores de proteína bruta (PB)

\begin{tabular}{|c|c|c|c|c|c|c|c|c|c|}
\hline \multirow{3}{*}{ Consumo } & \multirow{3}{*}{ Vaca } & \multicolumn{8}{|c|}{ PB no concentrado $(\%)$} \\
\hline & & 15,2 & 18,2 & 21,1 & \multirow[b]{2}{*}{ CV \% } & 15,2 & 18,2 & 21,1 & \multirow[b]{2}{*}{$\mathrm{CV} \%$} \\
\hline & & \multicolumn{3}{|c|}{$\mathrm{kg} / \mathrm{d}$} & & \multicolumn{3}{|c|}{$\% \mathrm{PV}$} & \\
\hline \multirow{3}{*}{$\begin{array}{l}\text { MS da dieta } \\
\text { total }\end{array}$} & $\mathrm{T}$ & 21,5 & 21,6 & 20,8 & & 4,5 & 4,5 & 4,3 & \\
\hline & $\mathrm{P}$ & $22,9 \mathrm{a}$ & $22,8 \mathrm{a}$ & $21,6 a$ & 4,8 & $5,1 \mathrm{a}$ & $5,0 \mathrm{a}$ & $4,8 \mathrm{a}$ & 5,5 \\
\hline & M & $20,8 b$ & $21,0 \mathrm{~b}$ & $20,3 b$ & & $4,1 b$ & $4,2 b$ & $4,1 b$ & \\
\hline \multirow{3}{*}{$\begin{array}{l}\text { MS do } \\
\text { capim- } \\
\text { elefante }\end{array}$} & $\mathrm{T}$ & 16,1 & 16,3 & 15,5 & & 3,3 & 3,4 & 3,2 & \\
\hline & $\mathrm{P}$ & $17,5 \mathrm{a}$ & $17,4 \mathrm{a}$ & 16,2 & 6,8 & $3,9 a$ & $3,8 \mathrm{a}$ & $3,6 a$ & 7,6 \\
\hline & M & $15,4 b$ & $15,7 b$ & 15,1 & & $3,1 b$ & $3,1 b$ & $3,0 \mathrm{~b}$ & \\
\hline \multirow{3}{*}{$\begin{array}{l}\text { FDN do } \\
\text { capim- } \\
\text { elefante }\end{array}$} & $\mathrm{T}$ & 10,7 & 10,7 & 10,3 & & 2,2 & 2,2 & 2,1 & \\
\hline & $\mathrm{P}$ & $11,6 \mathrm{a}$ & $11,5 \mathrm{a}$ & 10,7 & 6,8 & $2,6 \mathrm{a}$ & $2,5 \mathrm{a}$ & $2,4 \mathrm{a}$ & 7,6 \\
\hline & M & $10,2 b$ & $10,4 b$ & 10,0 & & $2,0 \mathrm{~b}$ & $2,1 b$ & $2,0 \mathrm{~b}$ & \\
\hline
\end{tabular}

Valores seguidos por letras distintas na mesma coluna diferem entre si pelo teste $\mathrm{t}(\mathrm{P}<0,05)$. 
Bargo et al. (2001) não observaram variação de consumo $(\mathrm{P}>0,05)$ por vacas multíparas alimentadas em pastagem com aveia (Avena sativa L. - $18,4 \%$ de PB na MS) e concentrado suplementar com $14,3 \% ; 23,3 \%$ ou $24,6 \%$ de PB na MS. Também Wales et al. (2000) registraram consumo semelhante $(\mathrm{P}>0,05)$ por vacas multíparas alimentadas em pastagem consorciada $(15,7 \%$ de PB na MS) e concentrado suplementar com $11,6 \% ; 20,5 \%$ ou $21,3 \%$ de PB na MS. Esses trabalhos mostraram que os menores teores de PB do concentrado foram suficientes para suplementar as forrageiras, sem comprometimento do consumo.

Neste experimento, observaram-se consumos bem mais altos que os 13,9 e $15,9 \mathrm{~kg}$ de $\mathrm{MS}$ total/dia ou os 2.653 e $2.677 \mathrm{~g}$ de $\mathrm{PB} /$ dia para primíparas e multíparas, respectivamente, recomendados pelo NRC (Nutrient..., 2001). As primíparas, ao receberem concentrado com 15,2; 18,2 ou $21,1 \%$ de $P B$, ingeriram $3.275 ; 3.455$ ou $3.629 \mathrm{~g} / \mathrm{d}$ de $\mathrm{PB}$, respectivamente. Da mesma forma, as multíparas ingeriram $3.053 ; 3.233$ ou $3.466 \mathrm{~g} / \mathrm{d}$ de PB.

Estimou-se que as dietas totais continham 14,7; 15,5 ou $16,5 \%$ de PB na MS. Estes valores são mais altos que o mínimo de $13,5 \%$ de PB na MS sugerido por Van Horn e Swanson (1976). Monteils et al. (2002) não encontraram diferença no consumo por vacas lactantes, ao compararem dietas totais com 13,0; 14,5 ou $16,0 \%$ de PB na MS $(2.243,2.625$ ou $3.018 \mathrm{~g} / \mathrm{d}$ de PB). Assim, acredita-se que a necessidade de consumo de PB por vaca/dia foi atendida com o concentrado suplementar com 15,2\% de PB, inclusive com certa folga, que atenderia situações com menor consumo de capim-elefante ou menor teor proteico da gramínea. Pode-se pensar numa redução maior do teor de PB do suplemento, inclusive com a utilização de apenas grãos energéticos na sua composição.

O consumo de MS total das primíparas foi maior $(\mathrm{P}<0,05)$ que o das multíparas $(22,4$ vs. $20,7 \mathrm{~kg} / \mathrm{d}$ de MS total, equivalendo a $5,0 \%$ e $4,1 \%$ do PV). Isso pode ser atribuído à maior exigência energética dessa categoria, associada à alta digestibilidade da dieta que, provavelmente, não limitou o consumo pelo fator físico e, sim, pelos fatores fisiológicos.

Não foram observadas diferenças $(\mathrm{P}>0,05)$ nas produções de leite sem ou com CPG em função dos tratamentos (Tab. 4). Estes resultados indicaram que, nessas condições, não foi necessário teor de $\mathrm{PB}$ acima de 15,2\% no concentrado suplementar. Os concentrados com maior teor de PB poderiam estar gerando desperdícios.

Bargo et al. (2001) não observaram diferenças ( $\mathrm{P}>0,05)$ nas produções de leite CPG $(19,0 ; 19,6$ e $20,8 \mathrm{~kg} / \mathrm{d})$ obtidas de vacas multíparas alimentadas em pastagem com aveia $(18,4 \%$ de PB) e concentrado suplementar com 14,3\%; $23,3 \%$ ou $24,6 \%$ de PB na MS. Wales et al. (2000) também encontraram produções de leite semelhantes $(21,3 ; 22,3$ e $21,8 \mathrm{~kg} / \mathrm{d} \mathrm{P}>0,05)$ de vacas multíparas alimentadas em pastagem $(15,7 \%$ de $\mathrm{PB})$ e concentrado suplementar com 11,$6 ; 20,5$ ou $21,3 \%$ de PB na MS.

Tabela 4. Produções de leite $(\mathrm{kg} / \mathrm{d})$ sem ou com correção para 4\% de gordura (CPG) de todas as vacas $(\mathrm{T})$, das primíparas $(\mathrm{P})$ e das multíparas $(\mathrm{M})$, alimentadas com capim-elefante sob pastejo e concentrado suplementar com diferentes teores de proteína bruta (PB)

\begin{tabular}{cccccc}
\hline \multirow{2}{*}{$\begin{array}{c}\text { Produção de leite } \\
(\mathrm{kg} / \mathrm{d})\end{array}$} & Vaca & \multicolumn{3}{c}{ PB no concentrado (\%) } & CV \% \\
\cline { 3 - 5 } & $\mathrm{T}$ & 17,5 & 18,2 & 21,1 \\
\hline \multirow{2}{*}{ Sem CPG } & $\mathrm{P}$ & $15,3 \mathrm{~b}$ & 17,2 & 17,6 & 4,4 \\
& $\mathrm{M}$ & $18,6 \mathrm{a}$ & $15,4 \mathrm{~b}$ & $15,6 \mathrm{~b}$ & \\
\hline \multirow{2}{*}{ Com CPG } & $\mathrm{T}$ & 16,1 & $18,2 \mathrm{a}$ & $18,7 \mathrm{a}$ & 5,0 \\
& $\mathrm{P}$ & $13,6 \mathrm{~b}$ & 15,8 & 16,4 & $13,9 \mathrm{~b}$ \\
& $\mathrm{M}$ & $17,3 \mathrm{a}$ & $13,7 \mathrm{~b}$ & $17,7 \mathrm{a}$ & \\
\hline
\end{tabular}

Valores seguidos por letras distintas na mesma coluna diferem entre si pelo teste $\mathrm{t}(\mathrm{P}<0,05)$. 
McCormick et al. (2001) e Aston et al. (1998) registraram aumento $(\mathrm{P}<0,05)$ na produção de leite, ao aumentarem o teor de PB do concentrado suplementar, para vacas com produções de leite ao redor de $30 \mathrm{~kg} / \mathrm{dia}$, e Monteils et al. (2002) não encontraram diferenças $(\mathrm{P}>0,05)$ na produção de leite, ao compararem dietas totais com 13,0;14,5 ou $16,0 \%$ de PB na MS.
Não foram observadas diferenças $(\mathrm{P}>0,05)$ nos teores de gordura, proteína e lactose em função dos diferentes teores de PB do suplemento (Tab. 5), isto é, o concentrado com mais de $15,2 \%$ de $\mathrm{PB}$ não proporcionou melhora na composição do leite.

Tabela 5. Teores de gordura, proteína e lactose no leite de todas as vacas (T), das primíparas (P) e das multíparas (M), alimentadas com capim-elefante sob pastejo e concentrado suplementar com diferentes teores de proteína bruta $(\mathrm{PB})$

\begin{tabular}{|c|c|c|c|c|c|}
\hline \multirow{2}{*}{$\begin{array}{c}\text { Componente do } \\
\text { leite }(\%)\end{array}$} & \multirow{2}{*}{ Vaca } & \multicolumn{3}{|c|}{ PB no concentrado $(\%)$} & \multirow{2}{*}{$\mathrm{CV} \%$} \\
\hline & & 15,2 & 18,2 & 21,1 & \\
\hline \multirow{3}{*}{ Gordura } & $\mathrm{T}$ & 3,44 & 3,46 & 3,53 & \multirow{3}{*}{4,3} \\
\hline & $P$ & $3,23 b$ & $3,28 b$ & $3,27 b$ & \\
\hline & M & $3,55 \mathrm{a}$ & $3,54 a$ & $3,66 \mathrm{a}$ & \\
\hline \multirow{3}{*}{ Proteína } & $\mathrm{T}$ & 2,86 & 2,87 & 2,92 & \multirow{3}{*}{3,0} \\
\hline & $\mathrm{P}$ & 2,83 & 2,83 & 2,90 & \\
\hline & M & 2,87 & 2,88 & 2,94 & \\
\hline \multirow{3}{*}{ Lactose } & $\mathrm{T}$ & 4,43 & 4,43 & 4,43 & \multirow{3}{*}{1,3} \\
\hline & $\mathrm{P}$ & $4,54 \mathrm{a}$ & $4,54 \mathrm{a}$ & $4,56 \mathrm{a}$ & \\
\hline & M & $4,37 b$ & $4,38 b$ & $4,36 b$ & \\
\hline
\end{tabular}

Valores seguidos por letras distintas na mesma coluna diferem entre si pelo teste $\mathrm{t}(\mathrm{P}<0,05)$.

Wales et al. (2000) não encontraram variações $(\mathrm{P}>0,05)$ nos teores de gordura, proteína $\mathrm{e}$ lactose no leite de vacas sob concentrados suplementares com diferentes teores proteicos. McCormick et al. (2001) observaram situações em que o suplemento mais proteico proporcionou maior $(\mathrm{P}<0,05)$ teor de gordura e proteína no leite. Entretanto, Bargo et al. (2001) registraram maior $(\mathrm{P}<0,05)$ teor de proteína no leite de vacas que receberam concentrado suplementar com menos PB, sem diferenças nos teores de gordura e lactose.

O leite das multíparas apresentou-se com maior $(\mathrm{P}<0,05)$ teor de gordura e menor $(\mathrm{P}<0,05)$ de lactose que o das primíparas.

$\mathrm{O}$ aumento do teor de $\mathrm{PB}$ do concentrado suplementar resultou em aumento $(\mathrm{P}<0,05)$ na concentração de NUP das vacas (Tab. 6).

Tabela 6. Concentração de nitrogênio-ureia no plasma (NUP) de todas as vacas (T), das primíparas (P) e das multíparas (M), alimentadas com capim-elefante sob pastejo e concentrado suplementar com diferentes teores de proteína bruta (PB)

\begin{tabular}{|c|c|c|c|c|}
\hline \multirow[t]{2}{*}{ NUP $\quad(\mathrm{mg} / \mathrm{dl})$} & \multicolumn{3}{|c|}{ PB no concentrado $(\%)$} & \multirow[b]{2}{*}{$\mathrm{CV} \%$} \\
\hline & 15,2 & 18,2 & 21,1 & \\
\hline $\mathrm{T}$ & $11,5 b$ & $12,2 b$ & $14,4 \mathrm{a}$ & \\
\hline $\mathrm{P}$ & $10,8 b$ & $12,2 \mathrm{ab}$ & $15,2 \mathrm{a}$ & 14,0 \\
\hline M & 11,9 & 12,1 & 14,1 & \\
\hline
\end{tabular}

Valores seguidos por letras distintas na linha diferem entre si pelo teste $\mathrm{t}(\mathrm{P}<0,05)$. 
Outros trabalhos mostraram que a concentração de NUP de vacas em lactação aumentou $(\mathrm{P}<0,05)$ quando os teores de PB da dieta aumentaram (Baker et al., 1995; Monteils et al., 2002). Bargo et al. (2001) não observaram aumento $(\mathrm{P}>0,05)$ de NUP $(12,5 ; 13,1$ e 13,8mg/dL) em vacas alimentadas em pastagens e concentrado suplementar com 15,3; 23,3 ou 24,6\% de PB na MS, respectivamente. $\mathrm{O}$ aumento de NUP observado no atual experimento pode sugerir princípio de excesso de nitrogênio no rúmen, sem assimilação pelos microrganismos. Valadares et al. (1997) sugeriram que, em novilhos, concentrações acima 13,5 a $15,5 \mathrm{mg} / \mathrm{dL}$ de NUP refletiriam perdas de compostos nitrogenados, enquanto Oliveira et al. (2001) indicaram que, em vacas em lactação, concentrações acima de $20 \mathrm{mg} / \mathrm{dL}$ de NUP ocasionariam esse tipo de perda. Lima et al. (2004) consideraram baixa a média de 9,8mg/dL de NUP, observada em vacas lactantes alimentadas exclusivamente em pastagem com capim-elefante, e associaram isso à baixa ingestão de proteína.

Não foram observadas diferenças $(\mathrm{P}>0,05)$ das concentrações de NUL (Tab. 7) das vacas alimentadas pelos diferentes concentrados suplementares.

Tabela 6. Concentração de nitrogênio-ureia no leite (NUL) de todas as vacas (T), das primíparas (P) e das multíparas (M), alimentadas com capim-elefante sob pastejo e concentrado suplementar com diferentes teores de proteína bruta $(\mathrm{PB})$

\begin{tabular}{ccccc}
\hline NUL $(\mathrm{mg} / \mathrm{dL})$ & \multicolumn{3}{c}{ PB no concentrado (\%) } & \multirow{2}{*}{ CV \% } \\
\cline { 2 - 4 } & 15,2 & 18,2 & 21,1 & \\
$\mathrm{~T}$ & 14,1 & 14,6 & 15,8 & 10,4 \\
$\mathrm{P}$ & 13,4 & 15,9 & 14,9 & \\
$\mathrm{M}$ & 14,5 & 14,0 & 16,3 & \\
\hline
\end{tabular}

A não da inclusão da fonte de variação animal, pelo abandono do delineamento em quadrado latino, e a utilização do delineamento em blocos ao acaso, devido à perda de dados do último período experimental, provavelmente, impossibilitou respostas mais claras.

Wales et al. (2000) observaram aumento de NUL ao aumentarem o teor proteico do concentrado suplementar para vacas sob pastejo. Outros autores também observaram esse comportamento ao aumentarem o teor de PB da dieta total (Lascano et al., 1991; Baker et al., 1995). Por isso, e também pela alta correlação entre o NUP e NUL (Baker et al., 1995), esperava-se aumento significativo $(\mathrm{P}<0,05)$ do NUL em função do aumento do teor proteico do concentrado.

Oliveira et al. (2001) e Lascano et al. (1991) consideraram que concentrações de 24 a $25 \mathrm{mg} / \mathrm{dL}$ de NUL seriam o limite a partir do qual se iniciariam perdas de compostos nitrogenados. Sato et al. (1996) relataram que vacas com variações de NUL acima de $18 \mathrm{mg} / \mathrm{dL}$ apresentaram resultados negativos de concepção após a inseminação.

De acordo com a literatura consultada, as concentrações de NUP e NUL estiveram próximas ao normal, e as dietas experimentais, independente da variação proteica, proporcionaram boa fermentação ruminal. Isso pode estar relacionado às características semelhantes de $\mathrm{pH}$, tipo de fermentação e flora bacteriana da polpa cítrica e do capim-elefante no rúmen, aliado ao sincronismo da degradabilidade e disponibilidade ruminal de energia e proteína dos alimentos utilizados (Van Soest, 1994; Scoton, 2003), que evitaram concentrações exageradas de NUP e NUL.

Na Tab. 8 estão relatados os pesos das vacas e suas variações durante os períodos experimentais.

Durante o experimento, as vacas ganharam peso e as primíparas tiveram ganhos de peso mais expressivos que as multíparas. A redução de peso durante $\mathrm{o}$ início do experimento (primeiro período) provavelmente ocorreu pela mudança da alimentação, pois, antes do início do experimento, os animais recebiam silagem de milho à vontade e maior quantidade de concentrado, em sistema de semiconfinamento, e passaram a ter como única fonte de volumoso o pasto. 
Tabela 8. Peso de todas as vacas $(\mathrm{T})$, das primíparas $(\mathrm{P})$ e das multíparas $(\mathrm{M})$, durante os três períodos experimentais (P1, P2 e P3)

\begin{tabular}{ccccccccc} 
Peso das & \multicolumn{3}{c}{ P1 } & \multicolumn{2}{c}{ P2 } & \multicolumn{2}{c}{ P3 } & Saldo \\
vacas $(\mathrm{kg})$ & Início & Final & Variação & Final & Variação & Final & Variação & final \\
\hline T & 486,2 & 483,3 & $-2,9$ & 483,0 & $-0,3$ & 489,4 & $+6,4$ & $+3,2$ \\
P & 449,3 & 446,3 & $-3,0$ & 452,7 & $+6,3$ & 458,3 & $+5,7$ & $+9,0$ \\
M & 504,7 & 501,8 & $-2,8$ & 498,2 & $-3,7$ & 505,0 & $+6,8$ & $+0,3$ \\
\hline
\end{tabular}

\section{CONCLUSÃO}

Nas condições do presente experimento, o concentrado com $15,2 \%$ de PB foi indicado para suplementar pastagens de capim-elefante, na alimentação de vacas em lactação.

\section{REFERÊNCIAS BIBLIOGRÁFICAS}

AROEIRA, L.J.M.; LOPES, F.C.F.; DERESZ, F. et al. Pasture availability and dry matter intake of lactating crossbred cows grazing elephant grass (Pennisetum purpureum, Schum.). Anim. Feed. Sci. Technol., v.78, p.313-324, 1999.

ASTON, K.; FISHER, W.J.; MCALLAN, A.B. et al. Supplementation of grass silage-based diets with small quantities of concentrates: strategies for allocating concentrate crude protein. Anim. Sci., v.67, p.17-26, 1998.

BAKER, L.D.; FERGUSON, J.D.; CHALUPA, $\mathrm{W}$. Responses in urea and true protein of milk to different protein feeding schemes for dairy cows. J. Dairy. Sci., v.78, p.2424-2434, 1995.

BARGO, F.; MULLER, L.D.; KOLVER, E.S. et al. Invited review: production and digestion of supplemented dairy cows on pasture. J. Dairy Sci., v.86, p.1-21, 2003.

BARGO, F.; REARTE, D.H.; SANTINI, F.J. et al. Ruminal digestion by dairy cows grazing winter oats pasture supplemented with different levels and sources of protein. J. Dairy Sci., v.84, p.2260-2272, 2001.

BENEDETTI, E. Atributos de três gramíneas tropicais, parâmetros ruminais e produção de leite em vacas mestiças mantidas a pasto. 1994. 173f. Tese (Doutorado) - Escola de Veterinária Universidade Federal de Minas Gerais, Belo Horizonte.

CORSI, M.; SILVA, S.C.; FARIA,V.P. Princípios de manejo do capim-elefante sob pastejo. Inf. Agropec., v.19, p.36-39, 42-43, 1998.
DERESZ, F. Influência do período de descanso da pastagem de capim-elefante na produção de leite de vacas mestiças Holandês x Zebu. Rev. Bras. Zootec., v.30, p.461-469, 2001.

LASCANO, C.; RODRÍGUES, J.C.; AVILA, P. Niveles de urea em leche como um indicativo del consumo de leguminosas tropicales por animales em pastoreo. Past. Trop., v.12, p.38-40, 1991.

LIMA, M.L.P.; BERCHIELLI, T.T.; LEME, P.R. et al. Concentração de nitrogênio ureico plasmático (NUP) e produção de leite de vacas mestiças mantidas em gramíneas tropicais sob pastejo rotacionado. Rev. Bras. Zootec., v.33, p.1616-1626, 2004.

LUCCI, C.S.; ROCHA, G.L.; FREITAS, E.A.N. Produção de leite em regime exclusivo de pastagens de capins fino e napiêr. Bol. Ind. Anim., v.29, p.45-51, 1972.

McCORMICK, M.E.; WARD, J.D.; REDFEARM, D.D. et al. Supplemental dietary protein for grazing dairy cows: effect on pasture intake and lactation performance. J. Dairy Sci., v.84, p.896-907, 2001.

MONTEILS, V.; JURJANZ, S.; BLANCHART, $\mathrm{G}$. et al. Nitrogen utilization by dairy cows fed diets differing in crude protein level with a deficit in ruminal fermentable nitrogen. Reprod. Nutr. Dev., v.42, p.545-557, 2002.

NUTRIENT requirements of dairy cattle. 7.ed. Washington: National Academy of Science, 2001. 408p.

OLIVEIRA, A.S.; VALADARES, R.F.D.; VALADARES FILHO, S.C. et al. Produção de proteína microbiana e estimativa das excreções de derivados de purina e de ureia em vacas em lactação alimentadas com rações isoproteicas com diferentes níveis de composto nitrogenados não proteicos. Rev. Bras. Zootec., v.30, p.16211629, 2001. 
PAULINO, M.F.; DETMANN, E.; VALADARES FILHO, S.C. et al. Soja grão e caroço de algodão em suplementos múltiplos para terminação de bovinos mestiços em pastejo. Rev. Bras. Zootec., v.31, supl., p.484-491, 2002.

PENATI, M.A. Estudo do desempenho animal e produção do capim Tanzânia (Panicum maximum Jacq.) em um sistema rotacionado de pastejo sob irrigação em três níveis de resíduo pós pastejo. 2002. 117f. Tese (Doutorado) Escola Superior de Agricultura Luiz de Queiroz, Universidade de São Paulo, Piracicaba, SP.

SALIBA, E.O.S.; RODRIGUES, N.M.; MORAES, D. et al. Purifild lignin extracted from Eucaliptus grandis (PELI), used as an external marker in digestbility trials in various animal species. World Conference Animal Production. 9., 2003, Porto Alegre, Brazil. Proceedings... Porto Alegre: WCAP, FV/UFRGS, 2003. p.1-9. CD-ROM.

SAMPAIO, I.B.M. Estatística aplicada à experimentação animal. 2.ed. Belo Hrizonte: FEP/MVZ, 2002. 264p.

SANTOS, F.A.P.; MARTINEZ, J.C.; VOLTOLINI, T.V. et al. Utilização da suplementação com concentrado para vacas em lactação mantidas em pastagens tropicais. In: SIMPÓSIO GOIANO SOBRE MANEJO E NUTRIÇÃO DE BOVINOS DE CORTE E LEITE, 5., 2003, Goiânia, GO. Anais... Goiânia: CBNA, 2003. p.289-346.

SATO, H.; NISHIGUCHI, Y.; KATO, T. Relations between milk urea levels and conception in lactating dairy cows. Anim. Sci. Technol. (Jpn), v.67, p.58-63, 1996.

SCOTON, R.A. Substituição do milho moído fino por polpa cítrica peletizada elou raspa de mandioca na dieta de vacas leiteiras em final de lactação. 2003. 55f. Dissertação (Mestrado) Escola Superior de Agricultura Luiz de Queiroz, Universidade de São Paulo, Piracicaba, SP.
SILVA, D.J. Análise de alimentos. Viçosa: Imprensa Universitária, 1990. 165p.

SILVA, M.M.P.; VASQUEZ, H.M.; SILVA, J.F.C. et al. Composição bromatológica, disponibilidade de forragem e índice de área foliar de 17 genótipos de capim-elefante (Pennisetum purpureum Schum.) sob pastejo, em Campos dos Goytacazes, RJ. Rev. Bras. Zootec., v.31, supl., p.313-320, 2002.

VALADARES, R.F.D.; GONÇALVES, L.C.; RODRIGUEZ, N.M. et al. Níveis de proteína em dietas de bovinos. 4. Concentração de amônia ruminal e ureia plasmática e excreções de ureia e creatinina. Rev. Bras. Zootec., v.26, p.1270$1278,1997$.

VALADARES FILHO, S.C.; ROCHA JUNIOR, V.R.; CAPPELLE, E.R. Tabelas brasileiras de composição de alimentos para bovinos. Viçosa: UFV, 2002. 297p.

VAN HORN, H.H.; SWANSON E.W. Protein levels for optimum performance. In: . Large dairy herd management. Gainesville: University of Florida. 1976. p.284-292.

VAN SOEST, P.J. Nutrition ecology of the ruminant. 2.ed. Ithaca: Cornell University, 1994. 476p.

VILELA, H.; CARNEIRO, G.G.; MOREIRA, H.A. Estudo do ganho de peso de bezerras Zebu e Holandesas em pastagem artificial de capimelefante (Pennisetum purpureum Schum.) estabelecida em solo de cerrado, durante a estação "chuvosa". Arq. Esc. Vet. UFMG, v.24, p.81-87, 1972.

WALES, W.J.; DELLOW, D.W.; DOYLE, P.T. Protein supplementation of cows grazing limited amounts of paspalum (Paspalum dilatatum Poir.)-dominant irrigated pasture in mid lactation. Austr. J. Exp. Agric., v.40, p.923-929, 2000. 